considered, yet there is room for a chapter on threonine deaminase (an interesting chapter on a rather exotic enzyme). However, the overall balance is good with the more unusual features of algae as plants, for example, the production of alginic acid and fucoidan being adequately dealt with.

The only disappointing part of the book is the plates which are poor; the paper is also thin, but there is a good stout cover and an adequate index. At $£ 18$ for over 500 pages packed with useful information I don't grudge a penny. I recommend it strongly to all with an interest in experimental phycology.

W. D. P. Stewart

W. D. P. Stewart is Professor and Head of the Department of Biological Sciences at the University of Dundee, UK.

\section{Neurochemistry and behaviour}

The Chemistry of Human Behaviour. By H. L. Meltzer. Pp. 261. (NelsonHall: Chicago, 1978.) \$17.95.

BELIEF in the chemical governance or in the chemical signatures of behaviour has some centuries of history but little current exposition in popular writing. This book, which attempts "a progress report for the informed layman" on "knowledge of brain chemistry and how this might relate to human behaviour" thus had a welcome objective, but neither the expressed objective nor the book's title should be taken literally. Their embodiment is a collection of specialist essays in neuroscience, with a preponderance of neurochemical studies in experimental animals.

The subjects covered are for the most part already well collated or reviewed elsewhere and the text bears only occassional evidence of orientation to the informed layman. Indeed some parts will puzzle the informed chemist: arbitrary variations in bondlength in structural formulae, and giving for glutamine the structure of asparagine. The book's merits lie in giving a largely correct account of several research themes of the past 10 or 20 years, in which chemical methods have been applied in understanding the structure or working of the brain and its influence on behaviour. These themes include malnutnition and brain development; inborn chemical abnormalities; the ion exchanges of nerve impulses; neurotransmitters; the actions of drugs including amphetamines, opiates, lysergic acid diethylamide, and steroid hormones; and chemical correlates of learning and of mental illness. The book's index and Figures are satisfactory, and it carries a 5-page list of books and reviews suggested for further reading. The penultimate chapter on ethical considerations is an excellent and timely exposition of the reasonable researcher's approach to experimentation with animals and human subjects. The chapters on flow of information and on the physical struc- ture of the brain, though non-chemical, are also apposite.

A book designated to give informed laymen an appreciation of a developing technical subject presents its own specific problems which have been met only partially by Dr Meltzer. His writing in general is crisp, factual and without involved sentences. Some chapters, however, are constructed to attract attention to an extent which, by the chapter's end, is disappointed. Some carry an introductory paragraph only tenuously related to the chapter's main subject; others imply by their title more than current knowledge justifies. Thus "The Chemical Organisation of the Brain" might lead the reasonable layman to expect an exposition of how and why the numerous chemical structures described and illustrated are organised, or organise other components, to yield a brain rather than another organ of the body. Here he will be disappointed and will learn only on the last of the 20 pages involved, that "This has been a brief survey of chemical localisation in the brain . . . intended as an introduction to the diversity of chemical function. ..."

The most successful expositions of technical knowledge of the brain for general readers have, recently, come from neurophysiology neuroanatomy or psychology. It is significant that the authors concerned with those expositions have not attempted to survey a large proportion of the current research in their subject: rather, they have chosen an intellectually intriguing theme central to their own interests and have been highly selective in the information presented to expound their viewpoints. Their pictures of the brain have included little if any neurochemistry at many points where neurochemistry would have been relevant. Comparably intriguing expositions from a neurochemical viewpoint have yet to be written: despite Dr Meltzer's book, the challenge remains open.

Henry Mcllwain

Henry Mcllwain is Professor of Biochemistry in the University of London at the Institute of Psychiatry (British Postgraduate Medical Federation), London, UK.
Investigating Animal Abundance

Capture-recapture for biologists

Michael Begon

By stressing the importance of biological context and the commonsense basis of the methods, this book aims to give biologists, at all levels, the confidence to use capture-recapture models for the assessment of animal population size, and to interpret the results they obtain sensibly.

The mathematical details of a variety of methods are treated in a clear and often novel way that requires little mathematical knowledge and there are useful sections on the actual techniques of capture and marking.

Paper $£ 3.95$

Publication March

\section{An Introduction to the Interpretation of Quantal Responses in Biology}

\section{P. S. Hewlett and R. L. Plackett}

This guide to the interpretation of quantal (all-or-none) responses to such agents as pesticides or drugs covers both probit and logit analysis, although the latter - which is mathematically the simpler - is given prominence. The authors deal in a distinctive manner with the theory of responses to mixtures of drugs, and discuss certain topics rarely touched on in other books: namely, dose-response curves for heterogeneous populations, the theory of monitoring insect populations for resistance, time and response, and the general nature of quantal responses.

Paper $£ 3.95$

Publication March

\section{Investigating \\ Chromosomes}

Adrian F. Dyer

This book strikes a balance between the theoretical and the practical aspects of cytogenetics. Assuming little prior knowledge, the local theoretical exposition is matched at every stage by practical sections that allow the student to investigate or visualise each stage of chromosome activity as it is introduced. All the practical routines are variations on one basic technique and are applied to a wide variety of plant and animal material.

Paper $£ 5$ approx

Publication Summer

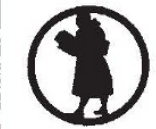

Edward Arnold

41 Bedford Square, London WC1B 3DQ 